\title{
Microencapsulamento de bactérias probióticas: uma breve revisão
}

\author{
Microencapsulation of probiotic bacteria: a brief review \\ Microencapsulación de bacterias probióticas: una breve revisión
}

Carolina Carvalho Ramos Viana

ORCID: https://orcid.org/0000-0002-1542-1612 EPAMIG - Instituto de Laticínios Cândido Tostes, Brasil E-mail:carolcrviana@yahoo.com.br

Isis Rodrigues Toledo Renhe

ORCID: https://orcid.org/0000-0003-3724-4060 EPAMIG - Instituto de Laticínios Cândido Tostes, Brasil E-mail: isis@epamig.br

Martha Eunice de Bessa

ORCID: https://orcid.org/0000-0002-8198-1773

Universidade Federal de Juiz de Fora, Brasil E-mail: marthaebessa@hotmail.com

Evandro Martins

ORCID: https://orcid.org/0000-0002-5448-8385 Universidade Federal de Viçosa, Brasil E-mail: evandromartins@ufv.br

Rodrigo Stephani

ORCID: https://orcid.org/0000-0003-0237-8325

Universidade Federal de Juiz de Fora, Brasil E-mail: rodrigo.stephani@ufjf.edu.br

Antônio Fernandes de Carvalho

ORCID: https://orcid.org/0000-0002-3238-936X Universidade Federal de Viçosa, Brasil E-mail: antoniofernandes@ufv.br

Ítalo Tuler Perrone

ORCID: https://orcid.org/0000-0002-3393-4876

Universidade Federal de Juiz de Fora, Brasil E-mail: italotulerperrone@gmail.com

\begin{abstract}
Resumo
No cenário econômico global, os probióticos têm sido responsáveis por uma expressiva movimentação financeira, e com crescimento progressivo esperado para os próximos anos. Busca-se cada vez mais otimizar a produção de culturas microbianas desidratadas, o que torna necessário o conhecimento sobre as técnicas disponíveis e já estudadas. O microencapsulamento se destaca por viabilizar a desidratação de microrganismos, de forma a proteger as células dos efeitos negativos da secagem. O objetivo deste artigo foi compilar dados da literatura sobre o microencapsulamento de probióticos, os principais agentes encapsulantes e métodos já estudados, com foco na secagem por atomização. Pode-se concluir com os trabalhos citados, que a estabilidade e viabilidade das culturas produzidas têm íntima relação com o agente encapsulante e o método utilizado para o microencapsulamento. Todavia, faz-se necessário a realização de mais pesquisas que tentem explicar o efeito protetor das condições utilizadas, de forma a direcionar para técnicas otimizadas na produção de culturas probióticas que sejam adequadas ao uso industrial.
\end{abstract}

Palavras-chave: Secagem de micro-organismos; Probióticos; Agente encapsulante; Cultura industrial; Spray dryer.

\begin{abstract}
In the global economic scenario, probiotics have been responsible for a significant financial movement, with progressive growth expected for the coming years. Therefore, the production of dehydrated microbial cultures needs to be optimized, making it necessary to know about the available and already studied techniques. Microencapsulation stands out for enabling the dehydration of microorganisms, protecting cells from the negative effects of drying. This article aimed to compile the literature on the microencapsulation of probiotics, the main encapsulating agents and methods already studied, focusing on drying by atomization. It can be concluded with the consulted literature that the stability and viability of the produced cultures are closely related to the encapsulating agent and the method used for microencapsulation. Further research is needed to explain the protective effect of the conditions used, to direct the optimization of techniques in the production of probiotic cultures that are appropriate for industrial use.
\end{abstract}

Keywords: Drying of microorganisms; Probiotics; Encapsulating agent; Industrial culture; Spray dryer. 


\section{Resumen}

En el escenario económico global los probióticos han sido responsables de un movimiento financiero significativo, con un crecimiento progresivo esperado para los próximos años. Se busca optimizar la producción de cultivos microbianos deshidratados, lo que hace necesario conocer las técnicas disponibles y ya estudiadas. La microencapsulación se destaca por permitir la deshidratación de microorganismos, con el fin de proteger las células de los efectos negativos del secado. El objetivo de este artículo es recopilar la literatura relacionada con la microencapsulación de probióticos, los principales agentes encapsulantes y métodos ya estudiados, centrándose en el secado por atomización. Se puede concluir con los estudios antes mencionados que la estabilidad y viabilidad de los cultivos producidos están estrechamente relacionadas con el agente encapsulante y el método utilizado para la microencapsulación. Un enfoque para próximas investigaciones es explicar el efecto protector de las condiciones utilizadas, con el fin de dirigir a técnicas optimizadas en la producción de cultivos probióticos que sean apropiados para uso industrial.

Palabras clave: Secado de microorganismos; Probióticos; Agente encapsulante; Cultivo industrial; Secador por pulverización.

\section{Introdução}

Um número crescente de micro-organismos tem sido investigado quanto ao seu potencial de conferir benefícios à saúde do hospedeiro, quando administrados em quantidades apropriadas, e tem sido amplamente utilizado em vários alimentos e bebidas (FAO / WHO, 2006; Huang et al., 2017; Marques et al., 2020).

Bactérias probióticas, como algumas cepas pertencentes ao gênero Lactobacillus, integram a microbiota intestinal humana e contribuem para o balanço do ecossistema microbiano do hospedeiro (Goldin, 2011; Liu et al., 2017; Miranda et al., 2021). Suas aplicações na indústria de alimentos incluem uso como culturas starter ou coadjuvantes no desenvolvimento de alimentos fermentados, incorporação em produtos alimentícios e como ingrediente com apelo funcional (Crovesy et al., 2017; Freire et al., 2021; Saad et al., 2013). Os benefícios ao hospedeiro incluem maior saúde digestiva e da pele, regularidade intestinal e fortalecimento do sistema imunológico (Abd El-Salam \& El-Shibiny, 2015; Chen et al., 2015; Figueiredo et al., 2020).

Para produzir tais efeitos benéficos na saúde, o probiótico deve ser capaz de sobreviver e se multiplicar no hospedeiro; deve ser metabolicamente estável e ativo no produto; resistir ao ambiente adverso durante a passagem gastrointestinal; e atingir o intestino em grande quantidade (Brasil, 2018; Martín et al., 2015; Sarao \& Arora, 2017).

A eficácia dos probióticos está relacionada à dose e, por isso, os alimentos probióticos devem conter pelo menos $10^{6} \mathrm{a}$ $10^{7}$ unidades formadoras de colônias viáveis por grama no momento de seu consumo (Abd El-Salam \& El-Shibiny, 2015; Brasil, 2018). O desafio é manter a viabilidade durante o processamento, armazenamento, vida de prateleira dos produtos, além de resistir aos estresses oxidativos, de temperatura e às alterações ácido-base a que os micro-organismos são submetidos nas matrizes alimentares.

Na maioria dos casos, o uso industrial de probióticos depende de métodos de preservação por meio da desidratação, com o intuito de garantir uma melhor viabilidade e atividade metabólica celular durante as aplicações alimentícias, processamento e armazenamento (Martins et al., 2019; Silva et al., 2014).

Várias tecnologias estão disponíveis para melhorar a conservação dos micro-organismos de interesse e produzir culturas industrialmente viáveis. A secagem é um dos processos aplicados, e que viabiliza uma vida útil estável e estendida. Entretanto, tem como fator limitante a perda de viabilidade principalmente devido à ruptura das células durante o processo (Dianawati et al., 2015; Huang et al., 2017; Rosolen et al., 2019).

De forma a proteger os micro-organismos dos efeitos negativos da secagem, a técnica de microencapsulamento pode ser aplicada. Esta tecnologia melhora a estabilidade bacteriana no processamento industrial, nos alimentos, bem como pode contribuir na redução da perda de viabilidade durante a passagem por condições enzimáticas e de $\mathrm{pH}$ adversos no trato gastrointestinal (Barroso et al., 2021; Dianawati et al., 2015; Panghal et al., 2018; Silva et al., 2014). 
Por ser uma técnica que vem se destacando na produção de culturas para uso na indústria de alimentos, o objetivo deste trabalho foi compilar, por meio de uma breve revisão, as principais informações científicas sobre o microencapsulamento de probióticos, tendo como foco o uso de spray drying como método de produção e descrição dos principais agentes encapsulantes empregados nos estudos.

\section{Metodologia}

O trabalho trata-se de uma revisão narrativa, de caráter qualitativo (Pereira et al., 2018). Baseia-se em pesquisas de bibliográficas em diferentes bases de indexação, em temas relacionados ao microencapsulamento de microrganismos probióticos, com foco no método por spray dryer. Buscaram-se artigos científicos adicionando as palavras-chave "microencapsulamento de microrganismos", "microencapsulamento de bactérias", "microencapsulamento de probióticos", "agentes encapsulantes, "spray dryer", "probióticos", "métodos de microencapsulamento".

Para a seleção dos artigos foram incluídas publicações em língua inglesa e portuguesa, majoritariamente entre os anos de 2011 à 2021.

\section{Referencial Teórico}

O microencapsulamento é uma técnica relativamente recente. Configura-se como uma tecnologia que promove o revestimento fino de partículas sólidas, gotas de líquidos, micro-organismos e dispersões (Barroso et al., 2021; Food Ingredients Brasil, 2013). O microencapsulamento é um processo de imobilização ou compartimentalização por cápsulas cujo tamanho está entre $1 \mu \mathrm{m}$ e $1000 \mu \mathrm{m}$. É uma tecnologia que vem sendo empregada na indústria de cosméticos, produtos farmacêuticos, agrotóxicos e alimentos e, nesta, é usado em aromas, ácidos, óleos, vitaminas, micro-organismos, entre outros (Martins et al., 2017).

Um possível design comumente usado para o encapsulamento de células microbianas envolve a microesfera, em que células vivas são incorporadas e imobilizadas aleatoriamente em uma matriz contínua. Portanto, os termos "imobilização" e "encapsulamento" são muitas vezes usados como sinônimo na maioria dos trabalhos relatados sobre a microencapsulamento de probióticos (Heidebach et al., 2012).

O microencapsulamento ajuda a proteger a célula microbiana do ambiente, melhorando assim sua estabilidade. A estrutura formada pelo agente de microencapsulamento em torno do núcleo é composta por um material semipermeável, ao mesmo tempo fino e relativamente forte (Kailasapathy, 2002). Além disso diminui as interações da substância encapsulada em relação aos fatores ambientais. Dessa forma preserva as características sensoriais e nutricionais alimentos, facilita a incorporação da substância encapsulada em sistemas secos e permite a liberação da substância encapsulada de forma lenta (Burgain et al., 2011; Kuang et al., 2010)

Conforme ilustrado na Figura 1, inúmeros são os benefícios do microencapsulamento microbiano, incluindo a proteção contra fatores prejudiciais para aumentar a resistência à secagem e armazenamento, e convertê-las em pó, de forma a facilitar o uso, pois melhoram a sua distribuição homogênea em todo o produto. 
Figura 1- Benefícios do microencapsulamento de probióticos.

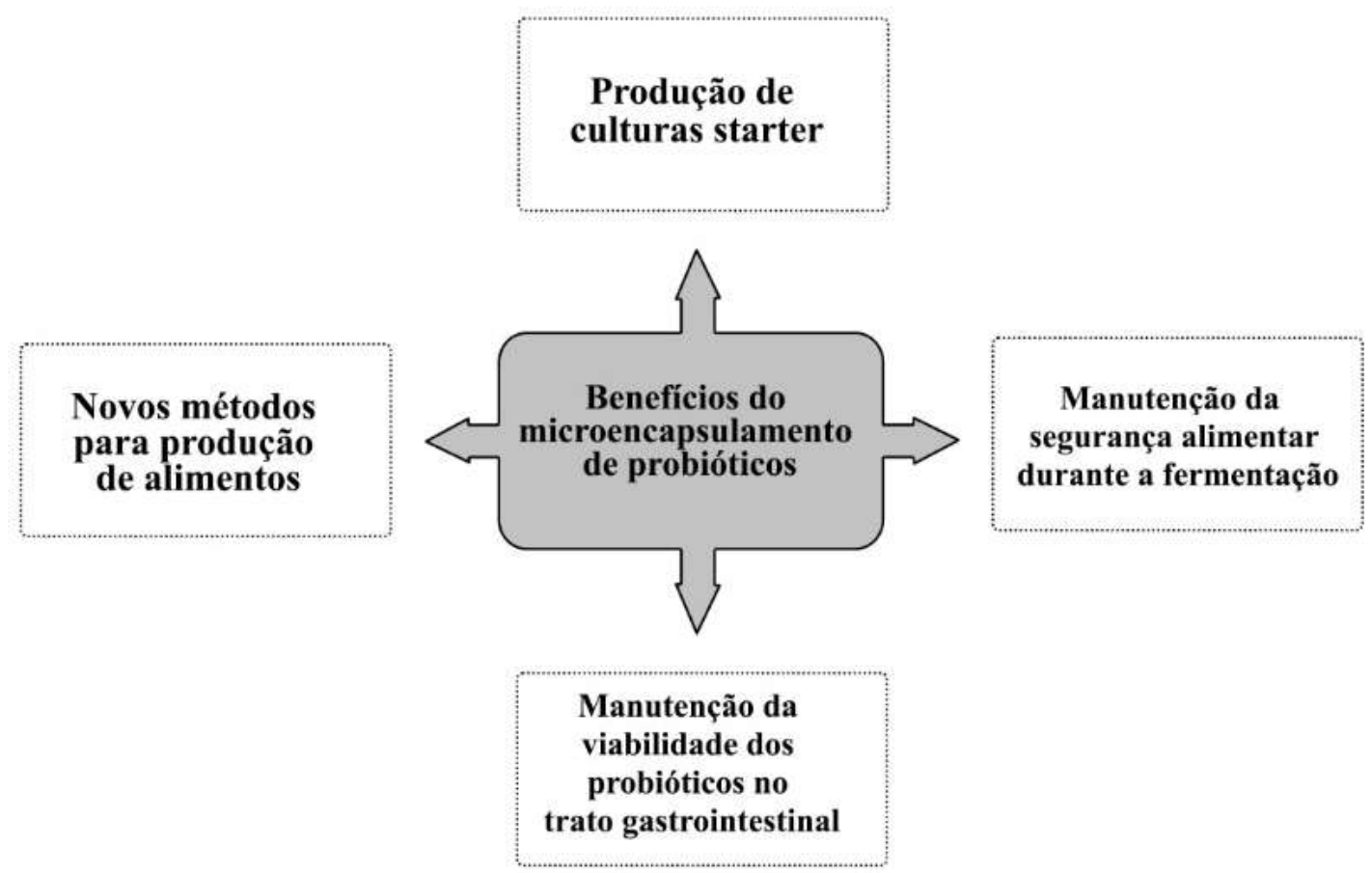

Fonte: Elaborado pelos autores, adaptado de Kavitake et al. (2017).

$\mathrm{Na}$ indústria alimentícia, essa técnica tem solucionado limitações no emprego de ingredientes, visto que pode suprimir ou atenuar flavors indesejáveis, reduzir a volatilidade e aumentar a estabilidade destes em condições ambientais adversas, como na presença de luz, oxigênio e pH extremos (Barroso et al., 2021).

A viabilidade dos probióticos encapsulados, bem como características das cápsulas formadas são afetada grandemente pelo processo de encapsulamento usado (Abd El-Salam \& El-Shibiny, 2015). Vários métodos de microencapsulamento são estudados, e há uma grande tendência de crescimento à medida que vão surgindo novos materiais encapsulantes e princípios ativos que requeiram processamentos específicos (Desai \& Park, 2005; Madene et al., 2006; Martín et al., 2015).

\subsection{Métodos de microencapsulamento de probióticos}

Geralmente, a tecnologia de microencapsulação é realizada incorporando-se células em uma matriz líquida. Após isso, a estabilização é realizada por um processo que pode ser físico (evaporação, solidificação), químico (polimerização) ou físicoquímico (gelificação), dependendo do material encapsulante utilizado (Barroso et al., 2021; Rokka \& Rantamäki, 2010; Sarao \& Arora, 2017).

Várias técnicas estão disponíveis para a desidratação e conservação de microrganismos. Dentre os métodos convencionais usados para o microencapsulamento de probióticos, destacam-se o método de extrusão, emulsificação e métodos de secagem, como spray drying e liofilização (Tabela 1) (Barroso et al., 2021; Chen et al., 2015; Silva et al., 2014).

A escolha do método mais adequado depende de características do material ativo, da aplicação e do mecanismo de liberação desejado para a sua ação. A diferença básica entre os métodos existentes está no tipo de envolvimento ou aprisionamento do material ativo pelo agente encapsulante, visto que a combinação entre o material e o agente ativo pode ser de natureza física, química ou físico-química (Food Ingredients Brasil, 2013; Rodrigues et al., 2020)

A extrusão é comumente empregada em função de baixo custo e simplicidade. Configura-se pela preparação de uma solução hidrocoloide adicionada dos probióticos, que é gotejada sob o material de revestimento por meio de um bico em alta 
pressão. Como agentes encapsulantes usados, pode-se citar o alginato, k-carragena e proteínas do leite (Huq et al., 2013; Kailasapathy, 2002; Silva et al., 2014; Vaniski et al., 2017).

A técnica de emulsão tem sido aplicada com sucesso para a microencapsulação de bactérias ácido láticas (BAL). Se comparado à extrusão, este método requer maior custo para desempenho (Huq et al., 2013). Realiza-se a dispersão de uma fase aquosa contendo as células bacterianas e suspensão em uma fase orgânica, como óleo, resultando em uma emulsão de água/óleo. As cápsulas formadas solidificam-se por meio de resfriamento ou adição de um agente gelificante (Kailasapathy, 2002; Martín et al., 2015; Vaniski et al., 2017).

O microencapsulamento de probióticos pode ser também feito por meio da secagem do concentrado de células. Dentre os mais importantes, observa-se a secagem em leito fluidizado, a liofilização e a secagem por spray dryer ou pulverização/atomização (Huq et al., 2013).

$\mathrm{Na}$ secagem em leito fluidizado, a suspensão de células é pulverizada e seca em transportadores inertes. Antes da secagem, é necessário que a cultura probiótica seja encapsulada em material de suporte, como alginato de cálcio, leite desnatado ou lipídeos (Martín et al., 2015).

A liofilização é um método que envolve a desidratação do material congelado sob um processo de sublimação a vácuo. É uma técnica comumente usada para preservar bactérias probióticas, uma vez que promove menor estresse às células e resulta em fermentos com maior viabilidade. Entretanto, produção de bactérias liofilizadas é limitada pelo longo tempo de processo, necessidade de armazenamento a baixas temperaturas e pelo alto custos energético demandado. Com isso, o emprego da técnica de spray drying vem se destacando (Martín et al., 2015; Martins et al., 2019; Silva et al., 2014).

Tabela 1 - Exemplos de processos de secagem comumente utilizados para microencapsulamento.

\begin{tabular}{|c|c|c|c|c|c|c|}
\hline Processo & \multicolumn{2}{|c|}{ Padrão de produção } & \multirow{2}{*}{$\begin{array}{c}\begin{array}{c}\text { Consumo } \\
\text { específico de } \\
\text { energia } \\
\left(\mathbf{k J}^{\prime} \cdot \mathbf{k g}^{-1} \mathbf{d e}\right. \\
\text { água })\end{array} \\
\\
11400\end{array}$} & \multirow{2}{*}{$\begin{array}{c}\begin{array}{c}\text { Produtividade } \\
\left(\text { ton·ano-1 }^{-1}\right)\end{array} \\
\text { n/d }\end{array}$} & \multirow{2}{*}{$\begin{array}{c}\text { Vantagens } \\
\text { Tratamento } \\
\text { térmico baixo; } \\
\text { produção de pó } \\
\text { abaixo da } \mathrm{T}_{\mathrm{g}}\end{array}$} & \multirow{2}{*}{$\begin{array}{c}\text { Limitações } \\
\text { Consumo de } \\
\text { energia muito } \\
\text { alto; alto tempo } \\
\text { de permanência } \\
\text { e investimentos }\end{array}$} \\
\hline $\begin{array}{c}\text { Secagem } \\
\text { por Leito } \\
\text { Fluidizado }\end{array}$ & $\begin{array}{l}\text { Sólido } \rightarrow \\
\text { Sólido }\end{array}$ & Contínuo & & & & \\
\hline Liofilização & $\begin{array}{l}\text { Líquido } \rightarrow \\
\text { Sólido }\end{array}$ & Lote & 18000 & $\sim 10000 *$ & $\begin{array}{c}\text { Tratamento } \\
\text { térmico muito } \\
\text { baixo; melhora } \\
\text { da reidratação }\end{array}$ & $\begin{array}{l}\text { Alto tempo de } \\
\text { residência }(24 \mathrm{~h} \text { a } \\
48 \mathrm{~h})\end{array}$ \\
\hline $\begin{array}{l}\text { Secagem } \\
\text { por spray } \\
\text { dryer }\end{array}$ & $\begin{array}{l}\text { Líquido } \rightarrow \\
\quad \text { Sólido }\end{array}$ & Contínuo & 5300 & $50000 *$ & $\begin{array}{c}\text { Baixo } \\
\text { Tratamento } \\
\text { térmico e tempo } \\
\text { de permanência }\end{array}$ & $\begin{array}{c}\text { Altos } \\
\text { invetimentos }\end{array}$ \\
\hline
\end{tabular}

n/d: Não descrito; Tg: Temperatura de transição vítrea

* valor aproximado para um secador em larga escala (a produtividade depende do equipamento e escala de produção).

Fonte: Elaborado pelos autores, adaptado de Huang et al., (2017)

Entre as técnicas de secagem possíveis, a secagem por spray dryer é uma das predominantes na indústria de laticínios para desidratação de produtos lácteos. Esse processo consiste na remoção parcial da água contida no produto, viabilizando o armazenamento, conservação por períodos mais longos e redução de custos logísticos (Schuck et al., 2012).

A secagem por pulverizaçãoo é uma das técnicas de microencapsulação mais amplamente utilizadas em função da capacidade de uso de vários agentes encapsulantes, estabilidade do produto final, fácil manuseio do equipamento, rápida solubilidade da cápsula, além do baixo custo (Alves et al., 2017). 
Conforme ilustrado na Figura 2, no microencapsulamento por spray dryer o material ativo a ser encapsulado é misturado a uma solução do composto que constitui o material encapsulante. Após isso, pulveriza-se tal mistura em gotículas finas $(10 \mu \mathrm{m}$ a $150 \mu \mathrm{m})$ que são direcionadas para um fluxo de ar quente e seco (geralmente $150^{\circ} \mathrm{C}$ a $250^{\circ} \mathrm{C}$ )(Martins et al., 2017; Schuck et al., 2012).

Figura 2- Princípio da secagem por atomização.

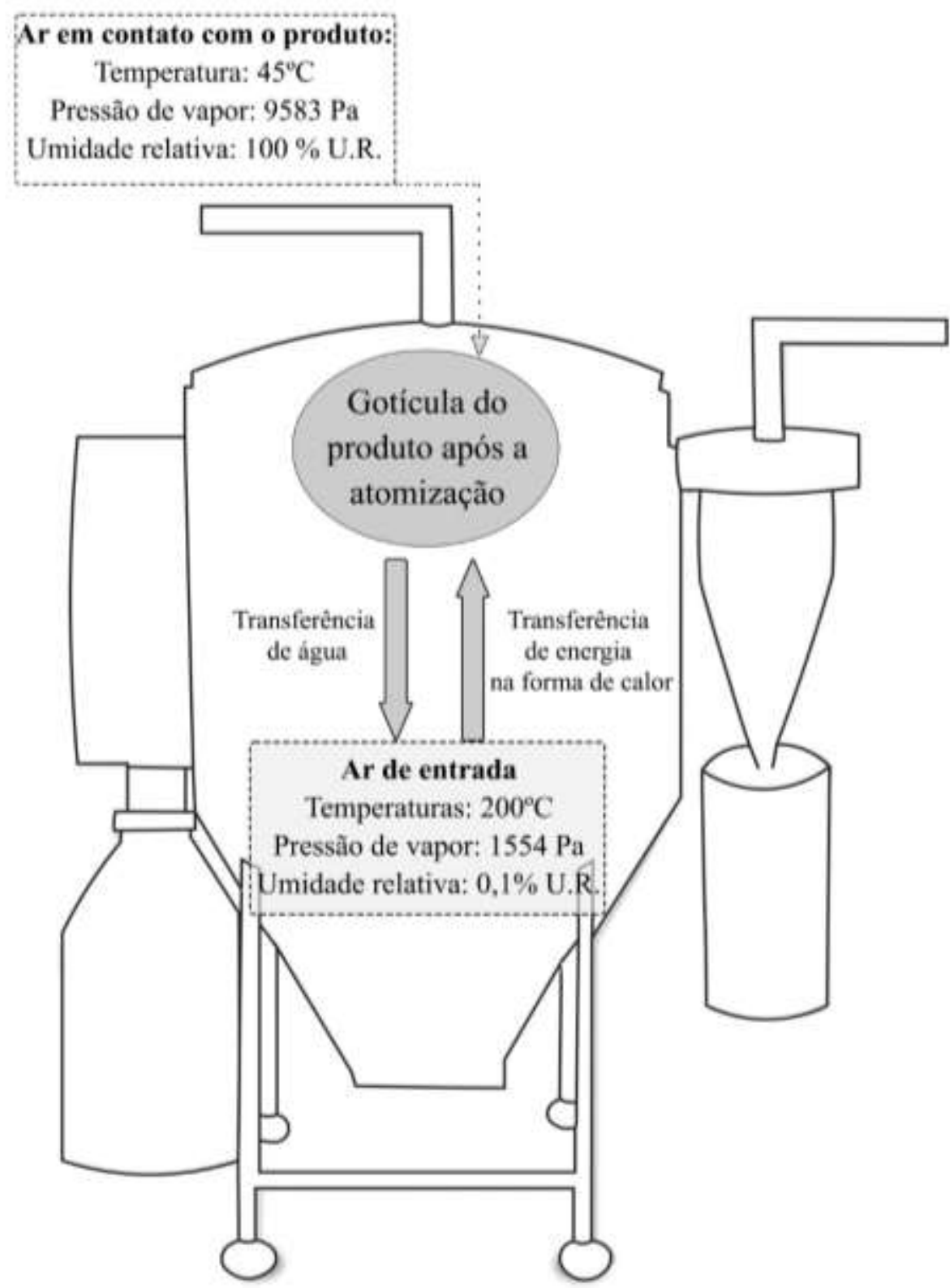

Fonte: Elaborado pelos autores, adaptado de Schuck et al., (2009).

Quando um produto entra em contato com uma corrente de ar tendo baixa umidade relativa (pressão de $1554 \mathrm{~Pa}$ ) e a temperatura elevada (em média $200^{\circ} \mathrm{C}$ ), é formada uma diferença de pressão e temperatura da água entre o produto e o ar. Por consequência, haverá uma transferência de energia na forma de calor do ar para o alimento e uma passagem de água do produto para o ar, conforme ilustrado na Figura 2. As gotículas que são formadas no interior da câmara possuem uma grande área superficial, o que leva a uma evaporação da água mais rápida em condição de temperatura mais baixa, o que reduz danos térmicos ao produto (Schuck, 2009). 
Esse processo apresenta algumas vantagens sobre os outros métodos: as propriedades e a qualidade do produto são mais eficientemente controladas; podem ser usados produtos sensíveis ao calor; há possibilidade de grandes produções em operação contínua com equipamento simples; produção de partículas relativamente uniformes e esféricas; boa eficiência e baixo custo do processo (Maciel et al., 2014)

Segundo Martin et al. (2015), a secagem por spray dryer é um método de microencapsulamento utilizado na indústria de alimentos por ser flexível e relativamente econômico. A vantagem do processo é que ele pode ser operado continuamente. A desvantagem é que a temperatura usada no processo pode não ser adequada para encapsular culturas bacterianas probióticas.

A fim de superar esta característica e melhorar as condições de sobrevivência de bactérias probióticas durante a secagem por atomização, vários métodos vem sendo estudados e desenvolvidos. O ajuste dos parâmetros de secagem por pulverização, como temperatura de entrada / saída, vazão, pressão do ar de atomização e tempo de permanência na câmara do secador, configuram-se como estratégias para melhorar viabilidade celular. Normalmente, usando temperaturas mais baixas de entrada / saída promove-se maiores taxas de sobrevivência de bactérias probióticas, em função do menor grau de dano térmico nas células (Liu et al., 2017). Além disso, escolher o material encapsulante mais eficiente é primordial no emprego desta técnica (Dianawati et al., 2015).

\subsection{Principais agentes encapsulantes estudados}

A escolha do material a ser utilizado como agente encapsulante deve considerar uma série de fatores, destancando-se propriedades físicas e químicas de compatibilidade destes em relação ao material a ser encapsulado. Em especial, a temperatura de transição vítrea do encapsulante, a superfície do núcleo encapsulado e fatores econômicos devem ser estudados (Martín et al., 2015; Rodrigues et al., 2020).

Os encapsulantes devem atender ainda aos seguintes requisitos: boas propriedades de formação de filme; baixa higroscopicidade; baixa viscosidade a altas concentrações de sólidos (menor que 0,5 Pa.s em concentrações superiores a 45\%); sabor e odor suaves; fácil reconstituição; e baixo custo. Na prática, em função da dificuldade em aliar tais características a um mesmo composto, são utlizadas misturas de materiais, de forma a obter melhores resultados em relação à viabilidade celular (Food Ingredients Brasil, 2013).

O tipo, concentração e propriedades do material capsular afetam marcadamente a viabilidade dos probióticos encapsulados. Inúmeros biomateriais, incluindo carboidratos (lactose, maltodextrina, alginato, amido, amidos modificados e sacarose), lipídios (monoglicerídeos, diglicéridos e óleos hidrogenados) e proteínas (caseína, proteínas do soro do leite, gelatina e albumina) já foram estudados e mostram-se com potencial para serem utilizados no encapsulamento de probióticos, e, além destes outros podem ser usados desde que satisfaçam aos requisitos dos materiais geralmente reconhecidos como seguros (status GRAS) (Abd El-Salam \& El-Shibiny, 2015; Antigo et al., 2020; Santos et al., 2014).

Segundo Dianawati; Mishra; Shah (2015) vários materiais de encapsulamento preparados a partir de carboidratos (álcoois de açúcar, açúcares, polissacarídeos, hidrocoloides) ou proteínas (à base de leite ou não) ou diversas combinações têm sido estudados, para verificar sua eficácia na proteção de bactérias probióticas. Leite desnatado e caseína e / ou açúcares como manitol, sorbitol, trealose e sacarose foram comprovadamente eficazes como materiais de encapsulamento de algumas cepas do gênero Lactobacillus. Por outro lado, o uso de polissacarídeos mostrou resultados variados, dependendo das cepas bacterianas e método de microencapsulamento, incluindo a etapa de liofilização ou spray. Cada um destes deve ser otimizado para aumentar a vida útil de bactérias probióticas sem alterações significativas nas suas características funcionais.

A pesquisa e desenvolvimento de novos biomateriais microencapsulante, tem sido uma área de crescente interesse contribuir para a eficácia na microencapsulamento de probióticos (Abd El-Salam \& El-Shibiny, 2015). 


\section{a) Carboidratos}

Os carboidratos são materiais muito utilizados para microencapsulamento, por sua capacidade de se ligar a compostos, além de sua diversidade e baixo custo. Entre os agentes protetores do tipo carboidrato, a trealose tem sido frequentemente investigada (Huang et al., 2017).

Outros compostos frequentemente estudados são o amido, a maltodextrina, a lactose e a goma xantana. $\mathrm{O}$ amido é um polissacarídeo de armazenamento constituídode unidades de $\alpha$ - D- glicose pelas ligações glicosídicas $\alpha 1 \rightarrow 4$ e $\alpha 1 \rightarrow 6$. Consiste em duas diferentes moléculas de polissacarídeos: uma é a amilose, com estrutura linear (20 a 30\%); e a outra é a amilopectina, de alta ramificação (70-80\%). A goma xantana mostra um comportamento bastante adequado à técnica de microencapsulamento devido à sua conformação semi-rígida e maior viscosidade, que leva a formar uma rede por ligação de hidrogênio e cadeia de polímero (Kavitake et al., 2018).

\section{b) Proteínas}

Proteinas são geralmente consideradas materiais adequados para microencapsulamento em aplicações alimentares, especialmente em alimentos líquidos e semi-sólidos. Possuem a vantagem de desenvolver matrizes de tamanhos controlados, sem qualquer efeito adverso no sabor dos alimentos (Abd El-Salam \& El-Shibiny, 2015). Além disso, podem apresentar efeitos estabilizadores desejáveis na textura dos alimentos.

A gelatina é uma mistura complexa de polipeptídeos de cadeia simples ou múltipla utilizada no encapsulamento probiótico. Este gel termo reversível pode ser usado sozinho ou em cooperação com polissacarídeos (Huq et al., 2013).

As propriedades funcionais e nutricionais únicas das proteínas do leite são bem documentadas (Fox \& McSweeney, 1998) e são universalmente valorizadas como ingrediente alimentar. Segundo Abd El-Salam; El- Shibiny (2015), as proteínas do leite têm várias vantagens específicas no microencapsulamento de compostos usados em alimentos:

1. Uma grande diversidade de produtos contendo proteína de leite está disponível comercialmente. Estes apresentam composição, teor de proteínas e propriedades funcionais diferentes. Podem apresentar caseínas, sais de caseinato, $\beta$-caseína, concentrados de proteína de soro de leite (WPC) e isolados (WPI) e $\beta$-lactoglobulina ( $\beta$-LG) e frações ricas em $\alpha$-lactalbumina $(\alpha$-LA). Isso oferece uma ampla gama de opções para encapsulamento de probióticos em proteínas do leite;

2. As proteínas do leite são flexíveis para encapsular qualquer tipo de substância hidrofílica, hidrofóbica ou células probióticas viáveis;

3. As proteínas do leite podem formar géis por meio de diferentes mecanismos em condições amenas. Isso oferece diferentes opções para o sucesso quanto ao uso de proteínas do leite no microencapsulamento de bactérias viáveis (Heidebach et al., 2012). A gelificação da caseína pode ser induzida com enzimas de coagulação do leite ou na presença de ácidos. A gelificação ácida da caseína ocorre próxima ao seu ponto isoelétrico, em que as interações hidrofóbicas atuam como as principais forças de agregação e gelificação. Além disso, a formação de novas ligações covalentes nas proteínas do leite pela ação da transglutaminase resulta na formação de géis;

4. As soluções concentradas de proteínas do leite têm viscosidades moderadas para facilitar a dispersão das células bacterianas e, quando usado no encapsulamento, fornece géis de alta densidade e melhor proteção para os probióticos aprisionados.

5. As proteínas do leite são fontes ricas de peptídeos bioativos de diferentes efeitos Tais peptídeos bioativos são gerados pela ação de enzimas do aparelho digestivo para exercer seus efeitos benéficos. Os peptídeos bioativos liberados podem oferecer um efeito sinérgico na ação probiótica. 
c) Lipídios

Ao contrário da aplicação de carboidratos e proteínas, o uso de lipídios para o encapsulamento de probióticos por spray dryer ainda não foi bem explorado. O encapsulamento matricial pode ser alcançado misturando células probióticas com lipídios liquefeitos e, com subsequente resfriamento. No entanto, a dispersão de concentrados de células probióticas no óleo foi relatado como uma tarefa tecnológica de difícil emprego (Heidebach et al., 2012).

Microcápsulas à base de gordura atualmente parece menos adequado para a combinação de encapsulamento probiótico comparados com microcápsulas à base de polissacarídeos ou proteínas. Porém, mais estudos são necessários para aprimoramento deste composto no microencapsulamento microbiano (Liu et al., 2017).

\section{Considerações Finais}

$\mathrm{O}$ aumento da demanda por alimentos funcionais, buscando-se benefícios nutricionais e à saúde deve impulsionar o crescimento deste mercado nos próximos anos. Além disso, a crescente procura por tratamentos não farmacológicos devido ao menor custo pode estimular a busca por alimentos probióticos, por serem amplamente utilizados no tratamento de distúrbios neurológicos, problemas digestivos e doenças mentais (Huang et al., 2017). Neste contexto, vê-se que a tecnologia de microencapsulamento pode ser ampla e diversificada.

Células bacterianas microencapsuladas têm sido amplamente relatadas como sendo mais estáveis do que células livres. Os efeitos do encapsulamento na estabilidade das culturas produzidas estão intimamente ligados ao agente encapsulante e método de secagem. No entanto, um meio adequado para secagem pode não ser eficaz na conservação da viabilidade celular, e por isso, entender as interações entre o encapsulante e o material a ser encapsulado é relevante para a eficiência deste processo.

A literatura atual sinaliza a necessidade por informações, bem como por pesquisa e desenvolvimento para produção culturas de probióticos com alto rendimento, alta viabilidade celular e baixo custo. Estudos limitados foram realizados sobre a interação entre encapsulantes e micro-organismos, e sinalizam a importância do conhecimento deste importante tópico para o aprisionamento bem-sucedido de probióticos.

Portanto, para pesquisas futuras, sugere-se avaliar e elucidar os mecanismos de proteção que ocorrem entre diferentes agentes encapsulantes e células, variando-se métodos e condições de microencapsulamento, a fim de evitar que a eficiência do processo utilizado seja determinada por tentativa e erro. Desta forma, será possível guiar a produção e uso de culturas microbianas para atender, de forma mais adequada, as necessidades industriais na produção de alimentos.

\section{Referências}

Abd El-Salam, M. H., \& El-Shibiny, S. (2015). Preparation and properties of milk proteins-based encapsulated probiotics: a review. Dairy Science and Technology, 95(4), 393-412. https://doi.org/10.1007/s13594-015-0223-8

Ahuja, K., \& Deb, S. (2018). Probiotics Market Size By Ingredients Bifidobacterium , Streptococcus , Bacillus ), By End-Use ( Human , Animal ), By Application ( Food and Beverages \{ Dairy Products , Non-Dairy Products , Cereals , Baked Food , Fermented Meat Products , Dry Food \}, Die. Food, Nutricion and Animal Feed, 260. https://www.gminsights.com/industry-reports/food-nutrition-and-animal-feed

Alves, A. I., Rodrigues, M. Z., Ribeiro Pinto, M. R. M., Lago Vanzela, E. S., Stringheta, P. C., Perrone, Í. T., \& Ramos, A. M. (2017). Morphological characterization of pequi extract microencapsulated through spray drying. International Journal of Food Properties, 20(June), 1298-1305. https://doi.org/10.1080/10942912.2017.1343344

Antigo, J. L. D., Silva, J., Bergamasco, R. C., \& Madrona, G. (2020). Microencapsulation of beet dye (Beta vulgaris L.) using maltodextrin and xanthan gum as encapsulant agents and application in yogurt. Research, Society and Development, 9(12), 1-25. https://doi.org/http://dx.doi.org/10.33448/rsd-v9i12.10896

Barroso, T. L. C. T., Alexandre, J. de B., Silva, L. C. da., Castelo, R. M., Ribeiro, L. B., Furtado, R. F., \& Zambelli, R. A. (2021). Tecnologia de encapsulamento na área de alimentos: Uma revisão. Research, Society and Development, 10(7), e6210716240. https://doi.org/10.33448/rsd-v10i7.16240

BRASIL. Ministério da Saúde/Agência Nacional de Vigilância Sanitária. (2018). Resolução da Diretoria Colegiada - RDC $n^{\circ} 241$, de 26 de julho de 2018. Edição:144. Seção: 1. Pág.97. 
Burgain, J., Gaiani, C., Linder, M., \& Scher, J. (2011). Encapsulation of probiotic living cells: From laboratory scale to industrial applications. Journal of Food Engineering, 104(4), 467-483. https://doi.org/10.1016/j.jfoodeng.2010.12.031

Chen, J., Wang, Q., Liu, C. M., \& Gong, J. (2015). Issues deserve attention in encapsulating probiotics: Critical review of existing literature. Critical Reviews in Food Science and Nutrition, 57(6), 1228-1238. https://doi.org/10.1080/10408398.2014.977991

Crovesy, L., Ostrowski, M., Ferreira, D. M. T. P., Rosado, E. L., \& Soares-Mota, M. (2017). Effect of Lactobacillus on body weight and body fat in overweight subjects: A systematic review of randomized controlled clinical trials. International Journal of Obesity, 41(11), 1607-1614. https://doi.org/10.1038/ijo.2017.161

Desai, K. G. H., \& Park, H. J. (2005). Recent developments in microencapsulation of food ingredients. In Drying Technology (Vol. 23, Issue 7). https://doi.org/10.1081/DRT-200063478

Dianawati, D., Mishra, V., \& Shah, N. P. (2015). Survival of Microencapsulated Probiotic Bacteria after Processing and during Storage: A Review. Critical Reviews in Food Science and Nutrition, 56(10), 1685-1716. https://doi.org/10.1080/10408398.2013.798779

FAO / WHO. (2006). Probiotics in food - Health and Nutrition Properties of and guidelines for evaluation. In FAO/ World Health Organization (Issue 1). FAO and WHO.

Figueiredo, M. C. F., Araújo, D. S., Nascimento, J. M. F., Moura, F. V. P., Silva, T. R., Barros, F. D. D. B., Medeiros, S. R. A., Olivera, V. A., Souza, A. C. P., \& Pereira-Freire, J. A. (2020). Efeitos dos probióticos sobre a microbiota intestinal e metabolismo de idosos. Research, Society and Development, 9(4), 116. https://doi.org/http://dx.doi.org/10.33448/rsd-v9i4.2969

Food Ingredients Brasil. (2013). Microencapsulação a serviço da indústria alimentícia. Food Ingredients Brasil, V. 25, 30-36. www.revista-fi.com

Fox, P. F., \& McSweeney, P. L. H. (1998). Dairy Science and Technology Handbook (First Edit). Blackie Academic \& Professional.

Freire, T. T., Silva, A. L., Ferreira, B. K. O., \& Santos, T. M. (2021). Bactérias ácido lácticas suas características e importância: revisão. Research, Society and Development, 10(11), 1-19. https://doi.org/http://dx.doi.org/10.33448/rsd-v10i11.19964

Goldin, B. R. (2011). Probiotics and health: From History to Future. In W. Kneifel \& S. Salminen (Eds.), Probiotics and Health Claims (p. 13). Blackwell Publishing Ltd. Blackwell. https://doi.org/10.1097/mcg.0b013e31822c5718

Heidebach, T., Först, P., \& Kulozik, U. (2012). Microencapsulation of Probiotic Cells for Food Applications. Critical Reviews in Food Science and Nutrition, 52(4), 291-311. https://doi.org/10.1080/10408398.2010.499801

Huang, S., Vignolles, M. L., Chen, X. D., Le Loir, Y., Jan, G., Schuck, P., \& Jeantet, R. (2017). Spray drying of probiotics and other food-grade bacteria: A review. Trends in Food Science and Technology, 63, 1-17. https://doi.org/10.1016/j.tifs.2017.02.007

Huq, T., Khan, A., Khan, R. A., Riedl, B., \& Lacroix, M. (2013). Encapsulation of Probiotic Bacteria in Biopolymeric System. Critical Reviews in Food Science and Nutrition, 53(9), 909-916. https://doi.org/10.1080/10408398.2011.573152

Kailasapathy, K. (2002). Microencapsulation of Probiotic Bacteria: Technology and Potential Applications. Curr. Issues Intest. Microbiol., 39-48.

Kavitake, D., Kandasamy, S., Devi, P. B., \& Shetty, P. H. (2018). Recent developments on encapsulation of lactic acid bacteria as potential starter culture in fermented foods - A review. Food Bioscience, 21(November 2017), 34-44. https://doi.org/10.1016/j.fbio.2017.11.003

Kuang, S. S., Oliveira, J. C., \& Crean, A. M. (2010). Microencapsulation as a tool for incorporating bioactive ingredients into food. Critical Reviews in Food Science and Nutrition, 50(10), 951-968. https://doi.org/10.1080/10408390903044222

Liu, H., Cui, S. W., Chen, M., Li, Y., Liang, R., Xu, F., \& Zhong, F. (2017). Protective approaches and mechanisms of microencapsulation to the survival of probiotic bacteria during processing, storage and gastrointestinal digestion: A review. Critical Reviews in Food Science and Nutrition, 59(17), 2863-2878. https://doi.org/10.1080/10408398.2017.1377684

Maciel, G. M., Chaves, K. S., Grosso, C. R. F., \& Gigante, M. L. (2014). Microencapsulation of Lactobacillus acidophilus La-5 by spray dryingusing sweet whey and skim milk as encapsulating materials. Journal of Dairy Science, 97(4), 1991-1998. https://doi.org/10.3168/jds.2013-7463

Madene, A., Jacquot, M., Scher, J., \& Desobry, S. (2006). Flavour encapsulation and controlled release - A review. International Journal of Food Science and Technology, 41(1), 1-21. https://doi.org/10.1111/j.1365-2621.2005.00980.x

Marques, C. G., Cruz, E. M. R. M. da, Bezerra, V. M., Costa, J. T. G., Lira, S. M., Holanda, M. O., Silva, J. Y., Canabrava, N., Silva, B. B., \& Guedes, M. I. F. (2020). Prebióticos e probióticos na saúde e no tratamento de doenças intestinais: uma revisão integrativa. Research, Society and Development, 9, 1-42. https://doi.org/http://dx.doi.org/10.33448/rsd-v9i10.9071

Martín, M. J., Lara-Villoslada, F., Ruiz, M. A., \& Morales, M. E. (2015). Microencapsulation of bacteria: A review of different technologies and their impact on the probiotic effects. Innovative Food Science and Emerging Technologies, 27, 15-25. https://doi.org/10.1016/j.ifset.2014.09.010

Martins, E., Cnossen, D. C., Silva, C. R. J., Cezarino, J. C., Nero, L. A., Perrone, I. T., \& Carvalho, A. F. (2019). Determination of ideal water activity and powder temperature after spray drying to reduce Lactococcus lactis cell viability loss. Journal of Dairy Science, 102(7), 6013-6022. https://doi.org/10.3168/jds.2019-16297

Martins, E., Poncelet, D., Rodrigues, R. C., \& Renard, D. (2017). Oil encapsulation techniques using alginate as encapsulating agent: applications and drawbacks. Journal of Microencapsulation, O(0), 754-771. https://doi.org/10.1080/02652048.2017.1403495

Miranda, B. L., Lima, D. O., Barbosa, T., Barbosa, M. L. M. R., Silva, H. J. N., Nascimento, E. M. M., Meira, D. E. A. V., Rocha, R. E., Kananda, P., Soares, T. S., Passos, C. R. F., Oliveira, T. P., Nascimento, A. C. O., Machado, K. C., \& Silva, A. M. (2021). Efeito dos probióticos na prevenção e tratamento de câncer e Diabetes mellitus. Research, Society and Development, 10(5), 1-9. https://doi.org/http://dx.doi.org/10.33448/rsd-v10i5.14932 
Research, Society and Development, v. 10, n. 13, e242101320814, 2021

(CC BY 4.0) | ISSN 2525-3409 | DOI: http://dx.doi.org/10.33448/rsd-v10i13.20814

Panghal, A., Janghu, S., Virkar, K., Gat, Y., Kumar, V., \& Chhikara, N. (2018). Potential non-dairy probiotic products - A healthy approach. Food Bioscience, 21, 80-89. https://doi.org/10.1016/j.fbio.2017.12.003

Pereira, A., Shitsuka, D., Parreira, F., \& Shitsuka, R. (2018). Metodologia da pesquisa científica. In UAB/NTE/UFSM (Ed.), Núcleo de Tecnologia Educacional da Uni- versidade Federal de Santa Maria (1st ed.). Universidade Federal de Santa Maria. https://repositorio.ufsm.br/bitstream/handle/1/15824/Lic_Computacao_Metodologia-Pesquisa-Cientifica.pdf?sequence=1. Acesso em: 03 de outubro de 2021.

Rodrigues, F. J., Cedran, M. F., Bicas, J. L., \& Sato, H. H. (2020). Encapsulated probiotic cells: Relevant techniques, natural sources as encapsulating materials and food applications - A narrative review. Food Research International, 137, 109682. https://doi.org/10.1016/j.foodres.2020.109682

Rokka, S., \& Rantamäki, P. (2010). Protecting probiotic bacteria by microencapsulation: Challenges for industrial applications. European Food Research and Technology, 231(1), 1-12. https://doi.org/10.1007/s00217-010-1246-2

Rosolen, M. D., Bordini, F. W., de Oliveira, P. D., Conceição, F. R., Pohndorf, R. S., Fiorentini, Â. M., da Silva, W. P., \& Pieniz, S. (2019). Symbiotic microencapsulation of Lactococcus lactis subsp. lactis R7 using whey and inulin by spray drying. Lwt, 115, 108411. https://doi.org/10.1016/j.1wt.2019.108411

Saad, N., Delattre, C., Urdaci, M., Schmitter, J. M., \& Bressollier, P. (2013). An overview of the last advances in probiotic and prebiotic field. LWT - Food Science and Technology, 50(1), 1-16. https://doi.org/10.1016/j.lwt.2012.05.014

Santos, R. C. S. dos., Finkler, L., \& Finkler, C. L. L. (2014). Microencapsulation of Lactobacillus casei by spray drying. Journal of Microencapsulation, 31(8), 759-767. https://doi.org/10.3109/02652048.2014.932026

Sarao, L. K., \& Arora, M. (2017). Probiotics, prebiotics, and microencapsulation: A review. Critical Reviews in Food Science and Nutrition, 57(2), 344-371. https://doi.org/10.1080/10408398.2014.887055

Schuck, P. (2009). Understanding the factors affecting spray-dried dairy powder properties and behavior. In Dairy-Derived Ingredients: Food and Nutraceutical Uses. https://doi.org/10.1533/9781845697198.1.24

Schuck, P., Dolivet, A., Méjean, S., Hervé, C., \& Jeantet, R. (2012). Spray drying of dairy bacteria: New opportunities to improve the viability of bacteria powders. International Dairy Journal, 31(1), 12-17. https://doi.org/10.1016/j.idairyj.2012.01.006

Silva, P. T. da., Fries, L. L. M., Menezes, C. R. de., Holkem, A. T., Schwan, C. L., Wigmann, É. F., Bastos, J. de O., \& Silva, C. de B. da. (2014). Microencapsulation: concepts, mechanisms, methods and some applications in food technology. Ciência Rural, 44(7), 1304-1311. https://doi.org/10.1590/0103-8478cr20130971

Vaniski, R., Corti, D., \& Drunkler, D. A. (2017). Técnicas e Materiais Empregados na Microencapsulação de Probióticos. Brazilian Journal of Food Research, 8(1), 156. https://doi.org/10.3895/rebrapa.v8n1.3651 